\title{
Assistência ao recém-nascido na sala de parto durante a pandemia de COVID-19
}

Assistance for newborns in the delivery room during the COVID-19 pandemic Atención al recién nacido en la sala de parto durante la pandemia de COVID-19

\author{
Camila Evangelista de Sousa Oliveira ${ }^{1}$ id https://orcid.org/0000-0002-1720-7011 \\ Mayara Águida Porfírio Moura1 id https://orcid.org/0000-0002-1608-2683 \\ Amanda Lúcia Barreto Dantas ${ }^{1}$ id https://orcid.org/0000-0003-1028-1451 \\ Márcia Teles de Oliveira Gouveia ${ }^{1}$ io https://orcid.org/0000-0002-2401-4947 \\ Victor Hugo Alves Mascarenhas² id https://orcid.org/0000-0003-2176-1514
}

\section{Como citar:}

Oliveira CE, Moura MA, Dantas AL, Gouveia MT, Mascarenhas VH. Assistência ao recém-nascido na sala de parto durante a pandemia de COVID-19. Acta Paul Enferm. 2021;34:eAPE03043.

DOI

http://dx.doi.org/10.37689/actaape/2021AR03043

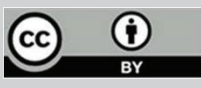

Descritores

Recém-nascido; Infecções por coronavírus; COVID-19; Pandemia; Parto; Enfermagem

obstétrica

Keywords

Infant, Newborn; Coronavirus infections; COVID-19; Pandemics; Parturition; Obstetric Nursing

\section{Descriptores}

Recién nacido; Infecciones por coronavirus; COVID-19; Pandemias; Parto; Enfermería obstétrica

\section{Submetido \\ 14 de Outubro de 2020 \\ Aceito \\ 5 de Março de 2021}

Autor correspondente

Camila Evangelista de Sousa Oliveira E-mail: camisevangelista@outlook.com

\section{Resumo}

Objetivo: Mapear as principais recomendações na assistência ao recém-nascido conforme o quadro clínico materno na sala de parto, tendo em vista o contexto da pandemia de COVID-19.

Métodos: Revisão de escopo baseada no método JBI. Foi utilizada a questão norteadora: "Quais as principais recomendações para a assistência ao recém-nascido na sala de parto durante a atual pandemia do coronavírus?". A seleção dos estudos foi realizada em bases de dados nacionais, internacionais e listas de referências. Dois revisores independentes realizaram a leitura dos textos completos, extração e análise dos dados, e sintetização do conteúdo.

Resultados: Foram incluídos 9 estudos que tiveram os dados sintetizados em um mapa de recomendações para assistência ao recém-nascido baseado no quadro materno para o novo coronavírus na sala de parto de acordo com os eixos de atenção: amamentação, contato pele a pele, clampeamento do cordão umbilical e assistência respiratória.

Conclusão: Na assistência ao recém-nascido na sala de parto deve-se adotar precauções para reduzir 0 risco de transmissão do vírus, realizar o contato pele a pele após a adoção de medidas de higiene, manter e estimular a amamentação exclusiva mediante cuidados de higiene da parturiente e realizar assistência respiratória em sala de pressão negativa por profissionais paramentados.

\section{Abstract}

Objective: To map the main recommendations for newborn care according to the maternal clinical picture in the delivery room, considering the COVID-19 pandemic context.

Methods: This is a scoping review based on the JBI method. The guiding question was: What are the main recommendations for assistance to newborns in the delivery room during the current coronavirus pandemic? Study selection was carried out in national and international databases and reference lists. Two independent reviewers read full texts, extracted and analyzed their data, and synthesized the content.

Results: We included 9 studies that had their data synthesized in a map of recommendations for assistance to newborns, based on the maternal condition for the new coronavirus in the delivery room according to the axes of attention breastfeeding, skin-to-skin contact, umbilical cord clamping, and respiratory assistance.

Conclusion: For newborn care in the delivery room, precautions should be taken in order to reduce the risk of virus transmission, make skin-to-skin contact after the adoption of hygiene measures, maintain and encourage exclusive breastfeeding through hygienic care of parturient women and perform respiratory assistance in a negative pressure room by trained professionals. 


\section{Resumen}

Objetivo: Mapear las principales recomendaciones para la atención al recién nacido según el cuadro clínico materno en la sala de parto, considerando el contexto de la pandemia de COVID-19.

Métodos: Revisión de alcance basada en el método JBI. Se utilizó la pregunta orientadora: “¿Cuáles son las principales recomendaciones para la atención al recién nacido en la sala de parto durante la pandemia de coronavirus?". La selección de los estudios fue realizada en bases de datos nacionales e internacionales y en listas de referencias. Dos revisores independientes realizaron a lectura de los textos completos, la extracción y el análisis de los datos y la síntesis del contenido.

Resultados: Se incluyeron nueve estudios, cuyos datos fueron sintetizados en un mapa de recomendaciones para la atención al recién nacido según el cuadro materno del nuevo coronavirus en la sala de parto, de acuerdo con los ejes de atención: lactancia, contacto piel con piel, pinzamiento del cordón umbilical y asistencia respiratoria.

Conclusión: En la atención al recién nacido en la sala de parto deben adoptarse precauciones para reducir el riesgo de transmisión del virus, realizar el contacto piel con piel luego de la adopción de medidas de higiene, mantener y estimular la lactancia exclusiva mediante cuidados de higiene de la parturienta y realizar asistencia respiratoria en sala de presión negativa por profesionales con traje de protección.

\section{Introdução}

Desde o início de fevereiro de 2020, a Organização Mundial da Saúde (OMS) passou a denominar oficialmente a doença causada pelo vírus SARS-CoV-2, de COVID-19. Atualmente, essa doença constitui uma Emergência de Saúde Pública de Importância Internacional (ESPIN), cujo andamento tem desafiado os sistemas de saúde e a sociedade em todo o mundo. ${ }^{(1,2)}$

Gestantes e puérperas foram considerados grupos de maior vulnerabilidade clínica para a COVID-19, pois apresentam alteração no mecanismo de imunidade e maior sensibilidade a hipóxia. (3-5) Tal situação associa-se a um maior número de desfechos negativos, como internaçóes e óbitos, e representa risco aumentado de transmissão da infecção para o recém-nascido $(\mathrm{RN})$. $^{(6,7)}$

No Brasil, a assistência a gestantes e puérperas confirmadas com o coronavírus encontra barreiras, tendo em vista as dificuldades presentes no cuidado obstétrico, como os obstáculos para o acesso ao serviço de saúde durante a pandemia. Associa-se isso à baixa disponibilidade de respiradores e cuidados intensivos para pacientes obstétricos com COVID-19, o que resulta em números elevados de mortes maternas e mal prognóstico para o $\mathrm{RN} .{ }^{(8)}$

A transmissão pós-natal ou horizontal do vírus para o RN é mais frequente e agrava-se quando a mãe é sintomática para COVID-19 devido a maior probabilidade do contato com gotículas ou material biológico contaminado. Nessa situação é preciso que haja adequaçóes na assistência para redução do risco de infecção na sala de parto. ${ }^{(6,9-12)}$
Diante disso, ressalta-se a importância da assistência humanizada ao RN no momento do parto e dos avanços conquistados para que o nascimento tenha menos intervençóes desnecessárias para a parturiente e RN. Entretanto, no contexto da pandemia deve-se priorizar a manutenção da vida e do bem-estar materno-infantil em detrimento da realização de açóes que podem aumentar o risco de contaminação do RN pelo SARS-CoV-2.. ${ }^{(12-14)}$

Com isso, compreendendo a emergência recente da COVID-19 no contexto mundial, essa revisão justifica-se pela necessidade de compreensão das principais recomendaçóes para assistência ao $\mathrm{RN}$ após o nascimento e pela reduzida produção nacional e internacional de estudos sobre o contexto de pandemia vivenciado, principalmente no que tange os cuidados com o RN.

Aliado a isso há evidências que discutem sobre a mortalidade materna por COVID-19 no Brasil, na qual é 3,5 vezes maior que a soma do número de mortes maternas reportados em outros países até julho deste ano. ${ }^{\left({ }^{(}\right)}$Tal dado é importante, pois pode interferir de forma significativa na saúde do RN.

Em uma busca preliminar na literatura científica, identificou-se uma lacuna de produção de conhecimento no que se refere a recomendaçóes direcionadas ao manejo neonatal na sala de parto, embora existam estudos que avaliam a transmissibilidade do vírus por diferentes vias. Assim, esse estudo objetivou mapear as principais recomendaçóes na assistência ao recém-nascido conforme o quadro clínico materno na sala de parto, tendo em vista o contexto da pandemia de COVID-19. 


\section{Métodos}

Trata-se de uma revisão de escopo, definida como uma forma de mapear a literatura existente em um determinado campo em termos de natureza, características e volume para identificar os principais conceitos que embasam determinada área do conhecimento. ${ }^{(15,16)}$ A escolha por esse método resultou do fato de até o momento trabalharmos com produção de conhecimento de baixo nível de evidência científica, tornando-se mais adequado reunir as informaçóes disponíveis por meio de uma revisão exploratória de grande alcance.

A revisão de escopo proposta foi conduzida de acordo com a metodologia JBI para análise de escopo. Para a elaboração do estudo utilizaram-se as seguintes etapas: identificação da questão norteadora ou de pesquisa; busca e seleção de estudos relevantes; seleção de estudos; mapeamento das informaçóes; agrupamento; resumo e relato dos resultados. ${ }^{(16,17)}$

Neste sentido, a questão do estudo construída por meio do mnemônico PCC foi: "Quais as principais recomendaçóes para a assistência ao recém-nascido na sala de parto durante a atual pandemia de covid-19?”. A escolha pela estratégia PCC é uma recomendação adequada às revisóes de escopo, na qual P (população): recém-nascido ("infant, newborn”), C (conceito): assistência na sala de parto (“delivery rooms"), C (contexto): pandemia de covid-19: ("coronavirus infections").

A busca de dados foi realizada nos meses de junho e julho de 2020 e obedeceu três passos para acesso ao máximo conteúdo de referências publicadas e não publicadas: a) Busca inicial de alta sensibilidade nos bancos de dados para identificar as principais palavras-chaves e descritores do tema: Medical Literature Analysis and Retrieval System Online (MEDLINE) via PubMed e Cumulative Index to Nursing and Allied Health Literature (CINAHL). b) Elaboração de uma estratégia de busca específica baseada nas palavras-chave e termos indexados específicos para os acervos: Web of Science, via Coleção Principal (Thomson Reuters Scientific); SCOPUS e Literatura Latino-Americana e do Caribe em Ciências da Saúde (LILACS), consultada pela Biblioteca Virtual em Saúde (BVS), acessadas pelo Portal CAPES; c)
As listas de referências de todos os artigos potencialmente elegíveis foram acessadas para identificar estudos adicionais.

A estratégia de busca ocorreu por meio dos descritores "infant, newborn", "coronavirus infections", "postnatal care", "delivery rooms", "birth setting" e "childbirth", identificados no Medical Subject Headings (MeSH), Títulos CINAHL e Descritores em Ciências da Saúde (DeCS). Esses termos foram combinados por meio de operadores booleanos "AND" e "OR" aos descritores não controlados: "newborn", "neonate", "neonates", "coronavirus infection", "covid19", "2019 novel coronavirus disease" e "birth".

Para inclusão das publicações na revisão, foram selecionados os seguintes critérios: artigos na íntegra, relatos de caso, editoriais, diretrizes, notas técnicas e recomendaçôes, nos idiomas inglês, espanhol ou português. Foram incluídos registros que apresentem informaçóes importantes para a condução da assistência independente da via de nascimento do RN nas primeiras horas após o parto. Foram excluídos artigos que não se adaptaram ou não possuíam informaçóes adequadas para atender à temática proposta.

Após a busca, todas citações potencialmente elegíveis foram agrupadas e importadas para o software EndNote Web, importante para a organização de referências e remoção de duplicatas. A seleção por meio da leitura de títulos e resumos, seguido pelo acesso de textos selecionados na íntegra foi realizada por dois revisores independentes. Todo o processo foi detalhado e ilustrado por meio de um fluxograma específico para a metodologia escolhida, a extensão Preferred Reporting Items for Systematic Reviews and Meta-analyses extension for scoping review (PRISMA-ScR). ${ }^{(18)}$

No processo de extração de dados das publicações selecionadas, utilizou-se uma adaptação do formulário da extraçáo de dados JBI, na qual acrescentaram-se itens específicos para a temática abordada, com base nos seguintes itens: ano, autores e país da publicação, objetivo, delineamento do estudo, população do estudo, contexto analisado, via de nascimento, principais resultados ou contribuiçôes acerca da assistência ao RN. ${ }^{(17)}$ 
Para que a produção de conhecimento identificada responda diretamente à questão de pesquisa, a síntese de dados ocorreu por meio de um mapa de recomendaçóes para a assistência prestada ao $\mathrm{RN}$, de acordo com o quadro clínico das mães (sintomáticas ou assintomáticas, porém confirmadas para COVID-19) na sala de parto. As demais informações extraídas foram discutidas em forma de narrativa, para descrever o estado de arte da literatura disponível.

\section{Resultados}

$\mathrm{Na}$ busca inicial foram obtidas 249 referências oriundas das pesquisas nos bancos de dados e 5 por meio da leitura de listas de referências dos potenciais artigos. Desse quantitativo, 103 estudos foram excluídos após remoção de duplicatas. Após isso, foi realizada a leitura do título e resumo de 151 artigos com posterior elegibilidade de 40 estudos. Destes, 9 artigos foram excluídos pela falta de disponibilidade do texto completo e 22 artigos devido a discordância com a questáo norteadora. Desta forma, foram incluídos 9 estudos para análise do texto na íntegra (Figura 1).

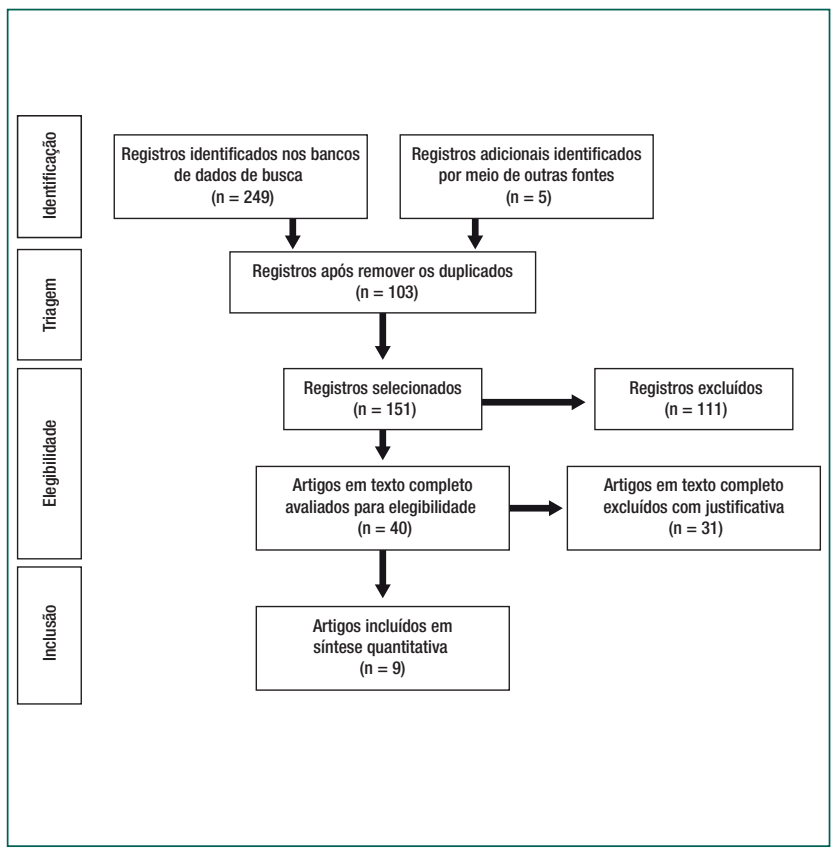

Figura 1. Fluxograma do processo de seleção dos estudos da revisão
Foram incluídos na revisão, um total de 9 estudos. Os dados dessas publicaçóes estão descritos no quadro 1 , no qual se identificam algumas características, como o título do estudo e do periódico, e país de origem. Todos foram publicados no ano de 2020 e nos seguintes países: Brasil $(n=3)$, Itália $(\mathrm{n}=2)$, Índia $(\mathrm{n}=1)$, Croácia $(\mathrm{n}=1)$, Estados Unidos $(n=1)$, Vietnã $(n=1)$. Em relação ao tipo de publicação e delineamento, foram inclusos: recomendaçôes $(\mathrm{n}=3)$, diretrizes $(\mathrm{n}=1)$, protocolos $(\mathrm{n}=1)$, artigo original $(n=1)$, editorial $(n=1)$ e notas técnicas $(n=2)$.

Quadro 1. Estudos incluídos pela revisão de escopo, segundo título, periódico, e país de origem

\begin{tabular}{|c|c|c|c|}
\hline Estudo & Título do estudo & $\begin{array}{l}\text { Título do } \\
\text { periódico }\end{array}$ & $\begin{array}{l}\text { País de } \\
\text { origem }\end{array}$ \\
\hline 1 & $\begin{array}{l}\text { Management of newborns exposed to mothers with } \\
\text { confirmed or suspected COVID-19. }{ }^{(19)}\end{array}$ & $\begin{array}{l}\mathrm{J} \\
\text { Perinatology }\end{array}$ & $\begin{array}{l}\text { Estados } \\
\text { Unidos }\end{array}$ \\
\hline 2 & $\begin{array}{l}\text { Breastfeeding and coronavirus disease-2019: Ad } \\
\text { interim indications of the Italian Society of Neonatology } \\
\text { endorsed by the Union of European Neonatal \& } \\
\text { Perinatal Societies. }{ }^{(20)}\end{array}$ & $\begin{array}{l}\text { Matern } \\
\text { Child Nutr }\end{array}$ & Itália \\
\hline 3 & $\begin{array}{l}\text { Nota Técnica n010/2020-COCAM/CGCIVI/DAPES/ } \\
\text { SAPS/MS. Atenção à saúde do recém-nascido no } \\
\text { contexto da infecção (SARS-CoV-2). }{ }^{(1)}\end{array}$ & - & Brasil \\
\hline 4 & $\begin{array}{l}\text { Perinatal-Neonatal Management of COVID-19 } \\
\text { Infection-Guidelines of the Federation of Obstetric } \\
\text { and Gynaecological Societies of India (FOGSI), National } \\
\text { Neonatology Forum of India (NNF), and Indian Academy } \\
\text { of Pediatrics (IAP) }{ }^{(21)}\end{array}$ & $\begin{array}{l}\text { Indian } \\
\text { Pediatr }\end{array}$ & Índia \\
\hline 5 & $\begin{array}{l}\text { Management of the mother-infant dyad with suspected } \\
\text { or confirmed SARS-CoV-2 infection in a highly } \\
\text { epidemic context.(22) }\end{array}$ & $\begin{array}{l}\text { J Neonatal } \\
\text { Perinatal } \\
\text { Med }\end{array}$ & Itália \\
\hline 6 & $\begin{array}{l}\text { Normas de biossegurança para prevenção da infeção } \\
\text { pelo SARS-CoV2 a serem adotadas nos serviços } \\
\text { de obstetrícia para atendimento ao parto e recém- } \\
\text { nascido. }{ }^{(23)}\end{array}$ & - & Brasil \\
\hline 7 & $\begin{array}{l}\text { Are Covid-19-positive mothers dangerous for their } \\
\text { term and well newborn babies? Is there an answer?(24) }\end{array}$ & $\begin{array}{l}\text { J Neonatal } \\
\text { Perinatal } \\
\text { Med }\end{array}$ & Croácia \\
\hline 8 & $\begin{array}{l}\text { Appropriate care for neonates born to mothers with } \\
\text { COVID-19 disease. }{ }^{(25)}\end{array}$ & $\begin{array}{l}\text { Acta } \\
\text { Pediatric }\end{array}$ & Vietnã \\
\hline 9 & $\begin{array}{l}\text { Neonatal COVID-19: little evidence and the need for } \\
\text { more information. }{ }^{(26)}\end{array}$ & $\begin{array}{l}\text { J Pediatr } \\
\text { (Rio J) }\end{array}$ & Brasil \\
\hline
\end{tabular}

A assistência ao RN na sala de parto foi ajustada com base no quadro clínico materno, quando há confirmação de infecção pelo novo coronavírus. Os cuidados são diferenciados em mães sem sinais para a infecção e mães suspeitas ou confirmadas para COVID-19, principalmente nos eixos de atenção ao clampeamento do cordão umbilical, contato pele a pele, amamentação e assistência respiratória. $\mathrm{O}$ mapa de recomendaçóes para a assistência apresenta uma síntese comparativa da assistência prestada aos recém-nascidos baseado no quadro clínico materno na sala de parto, conforme ilustra o quadro 2 . 
Quadro 2. Mapa de recomendações para a assistência ao recém-nascido baseado no quadro clínico materno para COVID-19 na sala de parto

\begin{tabular}{|c|c|c|}
\hline Eixos de Atenção & Mãe sem sinais de COVID-19 & Mãe suspeita ou confirmada para COVID-19 \\
\hline Amamentação & $\begin{array}{l}\text { Amamentação tão logo for possível, de preferência na primeira } \\
\text { hora de vida, ainda na sala de parto, além do aleitamento } \\
\text { materno exclusivo. }{ }^{27)}\end{array}$ & $\begin{array}{l}\text { Aleitamento materno por meio da expressão do leite seguindo os cuidados de } \\
\text { biossegurança, para evitar contágio. }{ }^{(19,2)} 0 \text { aleitamento direto no seio materno } \\
\text { deve ser permitido após adoção de medidas de precauções, como higiene da } \\
\text { mãe e uso de máscara cirúrgica. } \text {. }^{(1,21-26)}\end{array}$ \\
\hline Contato pele a pele & $\begin{array}{l}\text { Deve ser realizado em binômios materno-infantil com quadros } \\
\text { clínicos estáveis e assintomáticos, logo após o nascimento } \\
\text { para reduzir o risco de hipotermia e favorecer o aleitamento } \\
\text { materno. }{ }^{(28)}\end{array}$ & $\begin{array}{l}\text { Contato pele a pele imediato deve ser evitado frente a suspeita de COVID-19, } \\
\text { e recomenda-se a separação mãe-bebê, para realizar primeiros cuidados; } 19,22) \\
\text { recomenda-se o contato pele a pele precoce, após higiene corporal da mãe e } \\
\text { troca de EPI. } .^{(21,25,26)}\end{array}$ \\
\hline Clampeamento do cordão umbilical & $\begin{array}{l}\text { Pode ser realizado de forma tardia, caso RN nasça em } \\
\text { condições saudáveis, de } 1 \text { a } 3 \text { minutos após o nascimento. }{ }^{(28,29)}\end{array}$ & $\begin{array}{l}\text { Na idade gestacional } \geq 34 \text { semanas com tônus muscular em flexão e } \\
\text { respiração adequada ao nascimento, o clampeamento pode ser realizado } \\
\text { de forma oportuna. Em RN com idade gestacional }<34 \text { semanas indica-se } \\
\text { aguardar de } 30-60 \text { segundos antes de clampear o cordão umbilical. }{ }^{\left({ }^{30,31)}\right.}\end{array}$ \\
\hline Procedimentos respiratórios & $\begin{array}{l}\text { As recomendaç̃oes sugerem que devem ser realizados } \\
\text { por equipe multiprofissional capacitada e devidamente } \\
\text { paramentada com os equipamentos de proteção individuais } \\
\text { (EPI's) disponíveis. Podem ser realizados na sala de parto. }{ }^{(32)}\end{array}$ & 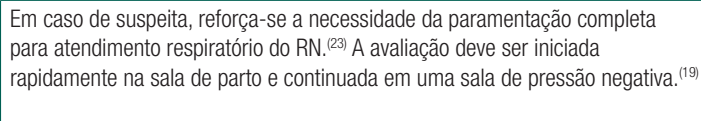 \\
\hline
\end{tabular}

\section{Discussão}

Essa revisão de escopo possibilitou mapear as principais recomendações ao $\mathrm{RN}$ de mães infectadas por COVID-19, de acordo com a situação clínica na sala de parto. Para tanto optou-se por apresentar a discussão dos dados por meio dos eixos de atenção relacionados na assistência, sendo eles: clampeamento do cordão umbilical, contato pele a pele, amamentação e assistência respiratória.

\section{Clampeamento oportuno do cordão umbilical}

O clampeamento oportuno do cordão umbilical (realizado de 1 a 3 minutos após o nascimento) constitui um dos cuidados essenciais ao RN e nas condições habituais é recomendado pela OMS por permitir a passagem continuada do sangue da placenta para o bebê durante um tempo maior e aumentar as reservas de ferro em até $50 \%$ aos 6 meses de idade em crianças nascidas a termo. ${ }^{(29)}$

Entretanto, o tempo preconizado para clampeamento oportuno do cordão umbilical pode apresentar algumas modificaçóes de acordo com a literatura consultada, tendo em vista o receio que ocorra a transmissão vertical do COVID-19 e pela urgência, em alguns casos, para separação do RN e mãe suspeita ou confirmada para o vírus. ${ }^{(24)}$

Com isso, os estudos selecionados apresentaram divergência quanto ao tempo para clampeamento oportuno do cordão umbilical. Alguns estudos recomendaram fazê-lo imediatamente após o nascimento para reduzir o risco de transmissão secundária do RN pelo vírus SARS-CoV-2. (21,24) Contraditoriamente, há a sugestão da permanência do clampeamento oportuno do cordão umbilical, tendo em vista os benefícios para o $\mathrm{RN}$ e a incerteza quanto às informaçóes disponíveis. ${ }^{(1,23,33)}$

Um estudo de revisão analisou os desfechos perinatais de 71 neonatos nascidos de máes que desenvolveram a infecção no terceiro trimestre. Dos casos relatados, um total de 4 recém-nascidos foram diagnosticados pelo exame RT-PCR realizado com amostras do cordão umbilical, dentro das primeiras 48 horas. A presença de IgG na amostra pode denotar a presença de anticorpos maternos transferidos ao recém-nascido, enquanto que a detecção de $\operatorname{IgM}$ indicaria resposta imune fetal. Nesse sentido, a escolha pelo momento oportuno do clampeamento pode trazer riscos e benefícios ao recém-nascido. Vale ressaltar que o RT-PCR é um exame mais específico do que sensível, o que possibilita maiores casos de falsos diagnósticos. ${ }^{(34)}$

Baseado nesses achados, a OMS e a Federação Brasileira das Associações de Ginecologia e Obstetrícia (FEBRASGO) preconizam recomendaçôes mais assertivas com relação ao clampeamento oportuno, sugerem que ele deve ser individualizado e analisado diante da idade gestacional e condição de saúde do RN. Na idade gestacional $\geq 34$ semanas com tônus muscular em flexão e respiração adequada ao nascimento, o clampeamento pode ser realizado de forma oportuna. Em RN com idade gestacional < 34 semanas indica-se aguardar de 30-60 segundos antes de clampear o cordão umbilical. ${ }^{(30,31)}$ 
Diante dos dados analisados, reforça-se a necessidade de atenção quanto aos riscos, benefícios e contextos individuais que são importantes para tomada de decisão. Para tanto, a análise individual das condiçôes clínicas materna e neonatal é necessária para que haja segurança no cuidado.

\section{Contato pele a pele}

$\mathrm{O}$ contato pele a pele (CPP) acontece quando o RN é colocado nu em contato direto com a pele do peito na mãe. O CPP “imediato" significa que o $\mathrm{RN}$ foi colocado em contato com a pele da mãe nos primeiros 10 minutos após o nascimento e no CPP "precoce", o contato ocorreu entre 10 minutos e 24 horas após o nascimento. Esse contato com a pele da mãe é apontado pela literatura como uma forma de adaptação do bebê à vida extrauterina e redução do risco de hipotermia. ${ }^{(35)}$

Esse tópico da assistência comumente realizado na sala de parto está em algumas situaçóes contraindicado diante da presença de sintomas do novo coronavírus apresentados pela parturiente, tendo em vista a possibilidade de infecção do RN. Dessa forma, estudos indicaram que o contato pele a pele seja evitado e que o manejo da mãe e bebê deve ser realizado de acordo com as condiçóes clínicas de ambos e os resultados de rastreamento da infecçáo pelo novo coronavírus. ${ }^{(1,21,22)}$

Para outro autor, além da recomendação de evitar o contato pele a pele, reforçou a necessidade da admissão da mãe sintomática para COVID-19 e RN em unidades hospitalares diferentes. Assim, após os procedimentos realizados na sala de parto, as mães devem permanecer em uma unidade diferenciada, para cumprir isolamento de ambas as partes. ${ }^{(19)}$ Com isso, segundo esse estudo tanto o CPP imediato como o precoce devem ser desencorajados e possivelmente algumas perdas podem acontecer para o binômio, como uma maior dificuldade em realizar amamentação diretamente no seio materno.

Esse dado pode ser entendido como medida de precaução adotada para evitar contaminação do $\mathrm{RN}$ pelo vírus, mas também como reflexo das diferentes políticas para promoção do vínculo e contato do binômio no pós-parto em diferentes países, que podem influenciar nas formas de enfrentamento à pandemia dependendo do contexto.

Por outro lado, outros estudos ressaltaram que o contato pele a pele do RN com a mãe pode ser realizado, quando a mesma encontra-se assintomática, pois constitui uma ação protetiva das consequências negativas de procedimentos prejudiciais, incluindo clampeamento precoce do cordão umbilical e aspiração de rotina, açóes que aumentam o contato com vários profissionais de saúde que podem estar infectados. ${ }^{(20,25,26)}$ Entretanto, é importante ressaltar que o CPP só poderá ocorrer quando forem adotadas todas as medidas de prevenção da contaminação do $\mathrm{RN}$, como: banho da puérpera, troca de máscara, touca, camisola e lençóis. ${ }^{(2)}$

Assim, é possível concluir o CPP deve ser desencorajado nos primeiros 10 minutos após o nascimento, tendo em vista que no período temporal considerado a parturiente ainda se encontra com secreçôes advindas do parto e que podem aumentar o risco de transmissão do SARS-CoV-2 para o RN. ${ }^{(25)}$

\section{Amamentação}

A amamentação, ainda na sala de parto, possibilita ao RN uma melhor adaptação a vida extrauterina e auxilia na regulação térmica, glicêmica e cardiorrespiratória. A sucção precoce, em especial para as mães, estimula a hipófise na produção de ocitocina e prolactina, aumentando a produção de leite pelo organismo. Além disso, o aleitamento na primeira hora de vida está associado a casos de maior sucesso no aleitamento materno exclusivo. ${ }^{(36)}$

No contexto da pandemia causada pelo novo coronavírus, algumas recomendaçóes sugeriram que a amamentação deve ser mantida diretamente no seio, caso o RN e mãe estejam clinicamente estáveis. Para tanto, a mãe deve utilizar máscara cirúrgica durante a amamentação do bebê e higienizar as mãos antes e após tocar o RN. ${ }^{(21,23)}$

Um estudo transversal retrospectivo realizado nos Estados Unidos vai ao encontro dessa informação ao orientar a permanência da amamentação de RN de mãe infectada após o parto e no alojamento conjunto. Tal recomendação é analisada como uma oportunidade educacional crítica ao proporcionar que as mães com COVID-19 aprenderem sobre 
precauçôes de isolamento, uso de equipamento de proteçấo individual e distanciamento seguro. ${ }^{(37)}$

$\mathrm{Na}$ sala de parto, em casos de suspeita ou confirmaçáo da mãe para COVID-19, alguns estudos recomendaram que a amamentaçấo deve ser adiada para o momento em que os cuidados de higiene e medidas de prevençáo da contaminação do $\mathrm{RN}$ fossem realizados, como limpeza da parturiente por meio do banho no leito, troca de camisola, lençóis, máscara e touca. ${ }^{(1,22,27)}$ Dessa forma, a amamentação não é desencorajada na perspectiva da infecção pelo COVID-19, tendo em vista a possibilidade de passagem de anticorpos maternos SARS-CoV-2 para o leite materno, e assim conferir imunidade contra o vírus ou reduzir a gravidade da infecção. ${ }^{(25)}$

Entretanto, outros autores não recomendaram a amamentação diretamente no seio materno, tendo em vista que o $\mathrm{RN}$ é separado da máe e internado em unidade hospitalar diferente. Nesses casos, sugere-se a expressão do leite materno com a adoção de medidas estritas de higiene para evitar possível transmissão da infecção por gotículas ou contato com secreções respiratórias, o leite também pode ser oferecido por um cuidador saudável. ${ }^{(19,20)}$

Nessa vertente, foi consenso entre os autores a manutenção do aleitamento materno exclusivo como forma de alimentaçáo do RN. Esse dado converge com o recomendado pelo Ministério da Saúde (MS), em que o leite materno é considerado padrão ouro na nutrição do RN. ${ }^{(27)}$ Dessa forma, acredita-se que os resultados encontrados nessa revisão se apoiaram nos benefícios advindos do ato de amamentar, que são, portanto, maiores que os riscos de transmissão do SARS-CoV-2 pelo leite materno.

\section{Assistência respiratória}

Os procedimentos respiratórios realizados nos RN podem aumentar o risco de transmissão aérea, principalmente para os profissionais de saúde que estão prestando o cuidado, tendo em vista que o SARS$\mathrm{CoV}-2$ pode permanecer no ar por um tempo superior a 3 horas e percorrer uma distância maior que 2 metros. ${ }^{(38,39)}$

Ainda na sala de parto, é sugerido que o RN que náo necessite de reanimação ou procedimentos respiratórios extensos, seja avaliado por um profissional capacitado para assistência neonatal imediatamente após o nascimento para avaliar aspectos como a cor, o tônus e o esforço respiratório. Caso a respiração seja espontânea e RN apresente bom tônus, o mesmo deve ser envolto com cobertas quentes e colocado em incubadora aquecida para transporte. ${ }^{(19)}$

Em consonância a essas informaçốes, uma nota técnica reforçou que os profissionais de saúde que realizam procedimentos respiratórios e manobras de reanimação devem utilizar avental de mangas longas estéreis, avental impermeável, gorro e máscara N95 para realização de procedimentos geradores de aerossóis, como: ventilação com pressão positiva manual, aspiração de vias aéreas, intubação e $\mathrm{CPAP}^{(23)} \mathrm{Na}$ necessidade de assistência respiratória ao $\mathrm{RN}$ suspeito para COVID-19, há a recomendação da avaliação inicial na sala de parto e a continuação dos cuidados em uma sala de pressão negativa. ${ }^{(19)}$

Além disso, reforça-se a que em situaçóes de assistência respiratória, o número de profissionais na sala deve ser minimizado e em uso de ventilação auxiliar, um tubo de sucção de pressão negativa pode ser colocado contendo uma extremidade de saída do ventilador conectado com um filtro e, em seguida, conectado a um dispositivo de sucção de pressão negativa, para que assim haja a redução na dispersão de partículas contaminadas com COVID-19. ${ }^{(4)}$

\section{Conclusão}

Apesar dos poucos relatos de identificação de anticorpos fetais em amostras do cordão umbilical, a definiçáo do clampeamento oportuno deve ser realizada por meio de análise individualizada, baseada em condiçôes obstétricas e neonatais. O CPP imediato está contraindicado, enquanto que o CPP precoce pode ser encorajado, desde que se evitem os riscos de contaminação do $\mathrm{RN}$ por meio das secreçôes corporais e gotículas respiratórias da mãe, após o banho da puérpera e a troca de EPI. Em relação a amamentação foi recomendado a permanência do aleitamento materno exclusivo, entretanto, enfatizou-se a adoção de medidas de higiene para realizaçáo do ato, como lavagem das mãos e uso de máscara. Para o RN que necessite de assistência respiratória, 
os cuidados devem ser realizados por profissionais devidamente paramentados para evitar a contaminação por aerossóis, em uma sala de pressão negativa. Consideram-se como limitaçóes observadas no desenvolvimento desta revisáo de escopo, a elevada quantidade de estudos publicados em chinês, o que impossibilitou o acesso dessas publicaçôes devido ao idioma. Além disso, houve dificuldade na análise dos estudos devido a divergência dos autores em relação as recomendaçóes para o cuidado ao RN na sala de parto, o que dificultou a possibilidade de fazer uma síntese da assistência mais assertiva. Diante do exposto, o mapeamento das principais recomendaçóes para assistência ao RN presente nessa revisão serve como direcionamento para a atuação dos profissionais na assistência ao binômio materno-infantil no contexto da atual pandemia. Além disso, os resultados aqui expostos apresentaram lacunas para a produção de novos estudos acerca do tempo de clampeamento do cordão umbilical e manejo do $\mathrm{RN}$ em outros cenários, como no alojamento conjunto e no momento da alta e pós-alta.

\section{Referências}

1. Brasil. Ministério da Saúde. Secretaria de Atenção Primária a Saúde. Nota Técnica n¹0/2020-COCAM/CGCIVI/DAPES/SAPS/MS. Brasília (DF): Ministério da Saúde; 2020 [citado 2020 Jun 25]. Disponível em: https://saude.rs.gov.br/upload/arquivos/202006/03180219-notatecnica10-2020-cocamcgcividapessapsms-003.pdf

2. Sociedade Brasileira de Pediatria (SBP). Recomendações para a assistência ao recém-nascido na sala de parto de mãe com COVID-19 suspeita ou confirmada. Rio de Janeiro: SBP; 2020 [citado 2020 Jun 26 2020]. Disponível em: https://www.sbp.com.br/imprensa/detalhe/ nid/recomendacoes-para-assistencia-ao-recem-nascido-na-sala-departo-de-mae-com-covid-19-suspeita-ou-confirmada/

3. Ayres JR, Calazans GJ, Saletti Filho HC, Franca Junior. Risco, vulnerabilidade e prática de prevenção e promoção de saúde. In: Campos GW, Minayo MC, Akerman M, Drumond Júnior M, Carvalho YM, Organizadores. Tratado de saúde coletiva. 2a ed. São Paulo: Hucitec; 2012.

4. Brigagão Jl, Caroci-Becker A, Baraldi NG, Felician RG, Venâncio KC, Mascarenhas VH. Recomendações e estratégias para o enfrentamento da Covid-19 durante a gestação, o parto, o pós-parto e nos cuidados com 0 recém-nascido. São Paulo: Boletim 2 - COVID-19; 2020 [citado 2020 Jun 23]. Disponível em: http://www5.each.usp.br/wp-content/ uploads/2020/04/BOLETIM-atualizado.pdf

5. Mascarenhas VH, Caroci-Becker A, Venâncio KC, Baraldi NG, Durkin AC, Riesco ML. COVID-19 and the production of knowledge regarding recommendations during pregnancy: a scoping review. Rev Lat Am Enfermagem. 2020;28:e3348.
6. Fan C, Lei D, Fang C, Li C, Wang M, Liu Y, et al. Perinatal transmission of COVID-19 associated SARS-CoV-2: should we worry? Clin Infect Dis. 2020 Mar 17:ciaa226.

7. Westgren M, Pettersson K, Hagberg H, Acharya G. Severe maternal morbidity and mortality associated with COVID-19: the risk should not be downplayed [editorial]. Acta Obstet Gynecol Scand. 2020;99(7):8156.

8. Takemoto ML, Menezes MO, Andreucci CB, Nakamura-Pereira M, Amorim MM, Katz L, et al. The tragedy of COVID-19 in Brazil: 124 maternal deaths and counting. Int J Gynaecol Obstet. 2020;151(1):154-6.

9. Dong L, Tian J, He S, Zhu C, Wang J, Liu C, et al. Possible vertical transmission of SARS-CoV-2 from an infected mother to her newborn. JAMA. 2020;323(18):1846-8.

10. Zeng $H, X u C$, Fan J, Tang Y, Deng $Q$, Zhang W, et al. Antibodies in infants born to mothers with COVID-19 pneumonia. JAMA. 2020;323(18):1848-9.

11. Dong $Y$, Mo X, Hu Y, Qi X, Jiang F, Jiang Z, et al. Epidemiological characteristics of 2143 pediatric patients with 2019 coronavirus disease in China. Pediatrics. 2020:e20200702.

12. Zhu H, Wang L, Fang C, Peng S, Zhang L, Chang G, et al. Clinical analysis of 10 neonates born to mothers with 2019-nCoV pneumonia. Transl Pediatr. 2020;9(1):51-60.

13. Livingston E, Bucher K. Coronavirus disease 2019 (COVID-19) in Italy. JAMA. 2020;323(14):1335.

14. Wu Z, McGoogan JM. Characteristics of and important lessons from the coronavirus disease 2019 (COVID-19) outbreak in China: summary of a report of 72314 cases from the Chinese Center for Disease Control and Prevention. JAMA. 2020;323(13):1239-42.

15. Peters MD, Godfrey CM, Khalil H, Mclnerney P, Parker D, Soares CB. Guidance for conducting systematic scoping reviews. Int J Evid Based Healthc. 2015;13(3):141-6.

16. Arksey H, O'Malley L. Scoping studies: towards a methodological framework. Int J Soc Res Methodol. 2005;8(1):19-32.

17. Peters MD, Godfrey C, Mclnerney P, Munn Z, Tricco AC, Khalil, $H$. Chapter 11: Scoping Reviews. In: Aromataris E, Munn Z, editors. JBI Manual for Evidence Synthesis. Australia: The Joanna Briggs Institute; 2020.

18. Tricco AC, Lillie E, Zarin W, O'Brien KK, Colquhoun H, Levac D, et al. PRISMA Extension for Scoping Reviews (PRISMA-ScR): Checklist and Explanation. Ann Intern Med. 2018;169(7):467-73.

19. Amatya S, Corr TE, Gandhi CK, Glass KM, Kresch MJ, Mujsce DJ, et al. Management of newborns exposed to mothers with confirmed or suspected COVID-19. J Perinatology. 2020;987-96.

20. Davanzo R, Moro G, Sandri F, Agosti M, Moretti C, Mosca F. Breastfeeding and coronavirus disease-2019: Ad interim indications of the Italian Society of Neonatology endorsed by the Union of European Neonatal \& Perinatal Societies. Matern Child Nutr. 2020;16(3):e13010. Review.

21. Chawla D, Chirla D, Dalwai S, Deorari AK, Ganatra A, Gandhi A, et al. Perinatal-Neonatal Management of COVID-19 Infection-Guidelines of the Federation of Obstetric and Gynaecological Societies of India (FOGSI), National Neonatology Forum of India (NNF), and Indian Academy of Pediatrics (IAP). Indian Pediatr. 2020;57(6):536-48.

22. Pietrasanta C, Pugni L, Ronchi A, Schena F, Davanzo R, Gargantini $G$, et al. Management of the mother-infant dyad with suspected or confirmed SARS-CoV-2 infection in a highly epidemic context. J Neonatal Perinatal Med. 2020;13(3):307-11. 
23. São Paulo. Prefeitura Municipal de São Paulo. Secretaria Municipal de Saúde. Coordenadoria de Vigilância em Saúde. Normas de biossegurança para prevenção da infeção pelo SARS-CoV2 a serem adotadas nos serviços de obstetrícia para atendimento ao parto e recém-nascido. São Paulo: Prefeitura Municipal de São Paulo; 2020 [citado 2020 Jul 1]. Disponível em: https://docs.bvsalud. org/biblioref/2020/06/1100233/nota_tecnica_08_obstetrica_ atendimento_parto_covid19.pdf

24. Stanojević M. Are Covid-19-positive mothers dangerous for their term and well newborn babies? Is there an answer? J Perinat Med. 2020;48(5):441-5.

25. Tran HT, Nguyen PT, Huynh LT, Le CH, Giang HT, Nguyen PT, et al. Appropriate care for neonates born to mothers with COVID-19 disease. Acta Paediatr. 2020;109(9):1713-6.

26. Procianoy RS, Silveira RC, Manzoni P, Sant'Anna G. Neonatal COVID-19: little evidence and the need for more information. J Pediatr (Rio J). 2020;96(3):269-72

27. Brasil. Ministério da Saúde. Secretaria de Atenção à Saúde. Departamento de Ações Programáticas e Estratégicas. Atenção à saúde do recém-nascido: guia para os profissionais de saúde. intervenções comuns, Icterícia e Infecções. 2a ed. vol. 2. Brasília (DF): Ministério da Saúde; 2014 [citado 2020 Jun 24]. Disponível em: https://bvsms.saude.gov.br/bvs/publicacoes/atencao_saude_recem_ nascido_v2.pdf

28. Brasil. Ministério da Saúde. Secretaria de Atenção à Saúde. Portaria $n^{\circ}$ 371, de 7 de Maio de 2014. Institui diretrizes para a organização da atenção integral e humanizada ao recém-nascido (RN) no Sistema Único de Saúde (SUS). Brasília (DF): Ministério da Saúde; 2014 [citado 2020 Jun 24]. Disponível em: https://bvsms.saude.gov.br/bvs/saudelegis/ sas/2014/prt0371_07_05_2014.html\#: :text=PORTARIA\%20 N\%C2\%BA\%20371\%2C\%20DE\%207,Considerando\%20os\%20Art

29. World Health Organization (WHO). Delayed clamping of the umbilical cord to reduce infant anaemia. Geneva: WHO; 2014 [cited 2020 Nov 20]. Available from: https://apps.who.int/iris/handle/10665/120074

30. Word Health Organization (WHO). Clinical management of COVID-19: interim guidance. Geneva: WHO; 2020 [cited 2020 Nov 20]. Available from: https://www.who.int/publications/i/item/clinical-managementof-covid-19

31. Federação Brasileira das Associações de Ginecologia e Obstetrícia (FEBRASG0). Protocolo de Atendimento no Parto, Puerpério e Abortamento durante a Pandemia da COVID-19. São Paulo:
FREBASGO; 2020 [citado 2020 Nov 20]. Disponível em: https://www. febrasgo.org.br/pt/covid19/item/1028-protocolo-de-atendimento-noparto-puerperio-e-abortamento-durante-a-pandemia-da-covid-19

32. Almeida MF, Guinsburg R. Programa de reanimação neonatal da sociedade brasileira de pediatria: condutas 2011. Sociedade Brasileira de Pediatria. São Paulo: SBP; 2021 [citado 2020 Nov 20] Disponível em: https://www.sbp.com.br/fileadmin/user_upload/pdfs/PRN-SBPReanimacaNeonatal-2011-24jan11.pdf

33. Mascarenhas VH, Caroci-Becker A, Venâncio KC, Baraldi NG, Durkin $\mathrm{AC}$, Riesco ML. Care recommendations for parturient and postpartum women and newborns during the COVID-19 pandemic: a scoping review. Rev Lat Am Enferm. 2020;28:e3359.

34. Lamouroux A, Attie-Bitach T, Martinovic J, Leruez-Ville M, Ville Y. Evidence for and against vertical transmission for severe acute respiratory syndrome coronavirus 2. Am J Obstetr Gynecol. 2020;223(1)E1-91. E4.

35. Moore ER, Bergman N, Anderson GC, Medley N. Early skin-to-skin contact for mothers and their healthy newborn infants. Cochrane Database Systematic Reviews. 2016;11:CD003519. Review.

36. Silva JL, Linhares FM, Barros AD, Souza AG, Alves DS, Andrade PD. Fatores associados ao aleitamento materno na primeira hora de vida em um hospital amigo da criança. Texto Contexto Enferm. 2018;27(4):e4190017.

37. Patil UP, Maru S, Krishnan P, Carroll-Bennett R, Sanchez J, Noble, L, et al. Newborns of COVID-19 mothers: short-term outcomes of colocating and breastfeeding from the pandemic's epicenter. J Perinatology. 2020;40(10):1455-8.

38. van Doremalen N, Bushmaker T, Morris DH, Holbrook MG, Gamble A, Williamson BN, et al. Aerosol and Surface Stability of SARS-CoV-2 as Compared with SARS-CoV-1. N Engl J Med. 2020;382(16):1564-7.

39. Zeng L, Xia S, Yuan W, Yan K, Xiao F, Shao J, et al. Neonatal EarlyOnset Infection With SARS-CoV-2 in 33 Neonates Born to Mothers With COVID-19 in Wuhan, China. JAMA Pediatr. 2020;174(7):722-5.

40. Wang L, Shi Y, Xiao T, Fu J, Feng X, Mu D, Feng Q, Hei M, Hu X, Li Z, Lu G, Tang Z, Wang Y, Wang C, Xia S, Xu J, Yang Y, Yang J, Zeng M, Zheng J, Zhou W, Zhou X, Zhou X, Du L, Lee SK, Zhou W; Working Committee on Perinatal and Neonatal Management for the Prevention and Control of the 2019 Novel Coronavirus Infection. Chinese expert consensus on the perinatal and neonatal management for the prevention and control of the 2019 novel coronavirus infection (First edition). Ann Transl Med. 2020;8(3):47. 